\title{
Experimental and Statistical Analysis of Formwork Beams Reinforced with CFRP
}

\author{
Krisztián Andor ${ }^{1}$, András Lengyel ${ }^{2 *}$, Rudolf Polgár ${ }^{3}$, Tamás Fodor ${ }^{1}$, Zsolt Karácsonyi ${ }^{1}$ \\ 1 Institute for Applied Mechanics and Structures, \\ University of Sopron, \\ H-9400 Sopron, Bajcsy-Zsilinszky u. 4., Hungary \\ 2 Department of Structural Mechanics, \\ Faculty of Civil Engineering, \\ Budapest University of Technology and Economics, \\ H-1521 Budapest, P.O.B. 91, Hungary \\ ${ }^{3}$ Universitas Fidelissima Kft. \\ University of Sopron, \\ H-9400 Sopron, Bajcsy-Zsilinszky u. 4., Hungary \\ *Corresponding author, e-mail: lengyel.andras@epito.bme.hu
}

Received: 29 August 2018, Accepted: 30 November 2018, Published online: 16 January 2019

\begin{abstract}
Enhancement of structural behaviour of various construction materials using fibre reinforced plastics (FRP) is an important branch of engineering research, including the increasing application for structural timber as well. This study deals with the reinforcement of standard construction formwork timber beams with carbon fibre reinforced plastics (CFRP). Beams with various amount of reinforcement were prepared using simultaneous formation of lamella and bonding. Laboratory bending tests are carried out and load-deflection data were measured to experimentally determine the change of load-bearing capacity and stiffness with respect to non-reinforced reference sample, as well as to assess the structural behaviour. Evaluation of failure modes is carried out on each specimen. A statistical analysis of the experimental results using t-test is also made. The experiments prove the enhancement of structural behaviour, especially in terms of the increased load-bearing capacity, the increased ductility in certain cases, the decrease of the scattering of results, and also in failure modes.
\end{abstract}

\section{Keywords}

timber formwork, CFRP, structural reinforcement, bending experiment, t-distribution

\section{Introduction}

Fibre reinforced plastics (FRP) are widely used in structural engineering in order to enhance mechanical performance of structural elements. The application for timber structures has now a few decades of history and its significance is growing. Its feasibility has been proven through various studies, though the complex mechanical behaviour of wood makes analysis more complicated.

Reinforcement materials are mostly glass fibres (GFRP) or carbon fibres (CFRP) and the wood material is mostly solid sawn timber (e.g. [1-3]), glued-laminated beams (e.g. $[4,5])$, or other structural elements. The subject of literature research includes not only new constructions but also reinforcement of existing structures, such as old historical building or bridges to extend service life (e.g. [6-8]).
Reinforcement elements also show large variety; they include sheets, fabrics, rods, connectors, pultruded elements, etc. Reinforcement is typically applied in the tension zone of the structural element, either externally, near the surface, embedded in notches, etc., see e.g. [7-10]. The bond is mostly provided by epoxy, which is also subject of some research.

The major aim of most research is to demonstrate that reinforcement improves structural performance either in terms of load-bearing capacity, stiffness, or ductility, etc. However, in spite of the diversity of research, clear conclusions are difficult to draw for various reasons. The main problem is that wood is an organic material with large deviation of material properties. Furthermore, species 
used in different application and geographic locations are naturally different to such a degree that results of individual studies are not convertible.

A majority of studies reports certain amount of increase in capacity, stiffness, and ductility. A full overview is literature is not intended here, though we mention that the increase in capacity is usually 20 to $50 \%[1,11]$ or more $[3,7,8]$, the increase of stiffness is typically small $[6,12]$ or sometimes higher $[2,7]$, and the increase of ductility is generally observed.

Another stream of research deals with numerical (FE) simulations of reinforced timber structures, see e.g. [1, 3-5, $8,12,13]$.

In a previous research carried out by the authors [14] full scale sawn timber beams made of Norway spruce were reinforced with CFRP fabric and tested for bending and a $30 \%$ average increase of capacity and $16 \%$ of stiffness was obtained, in accordance with projected objectives. The results are well within the typical range of values obtained for such cases. As mentioned, the large diversity of wood species results in a wide range of scattering data, within which the potential of Norway spruce could be determined [14]. The results proved that reinforcement with CFRP is a simple and effective way of enhancement of structural behaviour.

As mentioned above, FRP reinforcement of timber structural elements has been used covering a wide range of applications or structural types, such as enhancement of the behaviour of solid sawn beams or glulam beams for new constructions, retrospect reinforcement of old historical beams of different degree of degradation, etc. A possible novel application is the reinforcement of structural beams of formwork systems with the purpose of improving load-bearing capacity in an effective way. To the best of our knowledge no research has been published in this field.

In collaboration with Doka, this study deals with standard factory produced formwork beams, which are particularly designed to the needs of this application and differ significantly from ordinary solid beams. The beams are composite wood structural elements with solid sawn parts forming the flanges of the I-profile connected with a special flat compressed particle board as a web [15]. This design results in a relatively high flexural stiffness in terms of material weight while introducing the potential of new types of damages or failure modes.

The concept to reinforce formwork beams with FRP materials in order to improve structural behaviour and to potentially achieve better and optimized structural design is firmly supported by recent and past research regarding various wood products as mentioned above. Most importantly, a previous study by the authors [14] has proven that enhancement of load-bearing capacity, stiffness, and ductility of solid timber beams made of spruce is achievable at a low cost in terms of applied material, work force and technology.

The aim of this study is to conduct bending tests on composite formwork beams reinforced with CFRP in order to experimentally prove the improvement of load-bearing capacity and structural behaviour, to analytically and statistically evaluate measurement data, and to make a profound assessment on the mechanical behaviour of the complex reinforced system.

\section{Experiments}

Formwork beams provided by DOKA are uniform design factory beams with $1800 \mathrm{~mm}$ length under codenames H20 eco P or H20 top P. The beams had I-profile with 200 $\mathrm{mm}$ depths. The quality of timber used for the beams were the same for both types. The flanges were made of solid sawn spruce with $80 \mathrm{~mm}$ width and $40 \mathrm{~mm}$ depth while the web was made of wood particle boards $22 \mathrm{~mm}$ thick joined into the flanges (Figures 1 and 2).

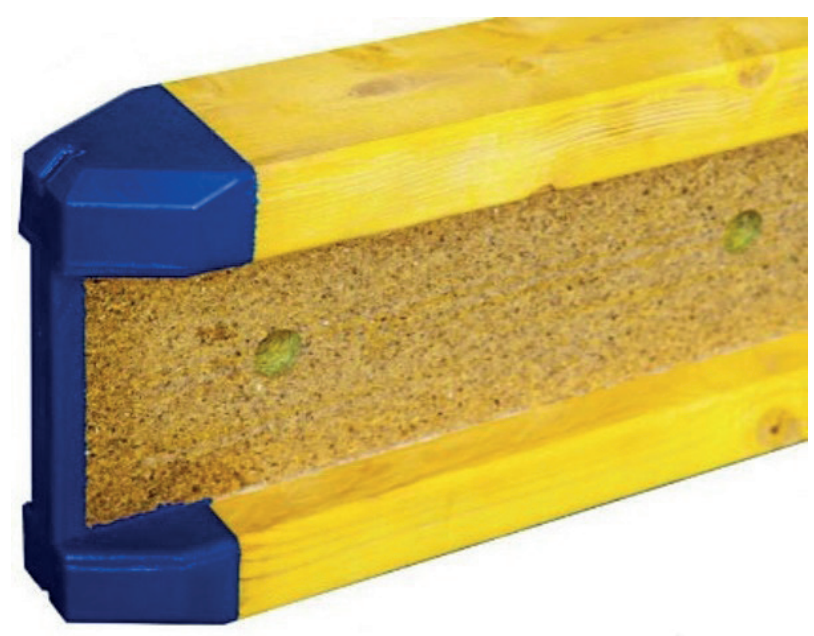

Fig. 1 Formwork beam composed of solid wood flanges and compressed particle board web [15]
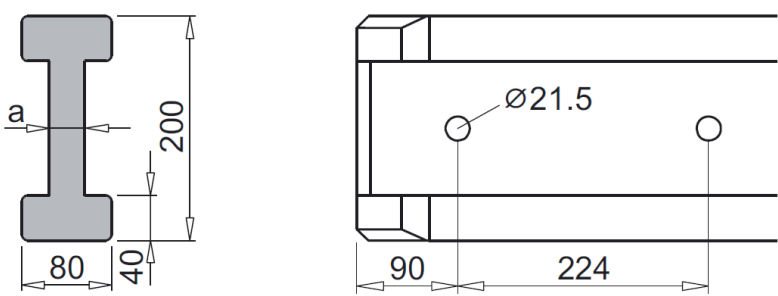

Fig. 2 Formwork beam cross-section and dimensions [15] 
Some of the beams were tested without reinforcement both to have generic assessment on the behaviour and to form a reference. The rest of the specimens were fitted with a single layer of CFRP strip along the full length of the tension side. The width of the strip was either equal to that of the flange or half of it in order to analyse different amount of reinforcement. The carbon fibre material was a unidirectional fabric with $99 \%$ of fibres in longitudinal direction and $1 \%$ in weft. Specific amount of the fabric was approx. $300 \mathrm{~g} / \mathrm{m}^{2}$. The embedding matrix was formed with synthetic two-component epoxy especially developed for reinforcing fibres provided by Sika [16]. The amount of epoxy used was approx. $0.5 \mathrm{~kg} / \mathrm{m}^{2}$. The application of the glue is straightforward and perfect bond is formed with both the fibres and the timber as demonstrated previously by the authors [14].

The bending tests were carried out by a standard MTS testing device with capacity of $250 \mathrm{kN}$ (Figure 3). The specimens were simply supported with span of $1600 \mathrm{~mm}$ and the load was applied on the top flange by a single hydraulic actuator in the middle of the span distributed over $40 \mathrm{~cm}$ distance. During the operation of the testing device the load is slowly increased while it was digitally recorded every 0.5 seconds. The deflections at mid-span were simultaneously measured and recorded by a video-extensometer. The loading process was carried on until failure of the specimens.

The number of beam specimens without reinforcement, with a full width reinforcement, and half width reinforcement was 7, 11, and 5, respectively, giving a total of 23 .

Inspection during and after the test revealed that one specimen in the group of beams reinforced at full width was invalid because the connection between the web and the upper flange was defective and hence unable to carry load and it led to a localized damage. This specimen was omitted from the sample since it did not represent valid measurement.

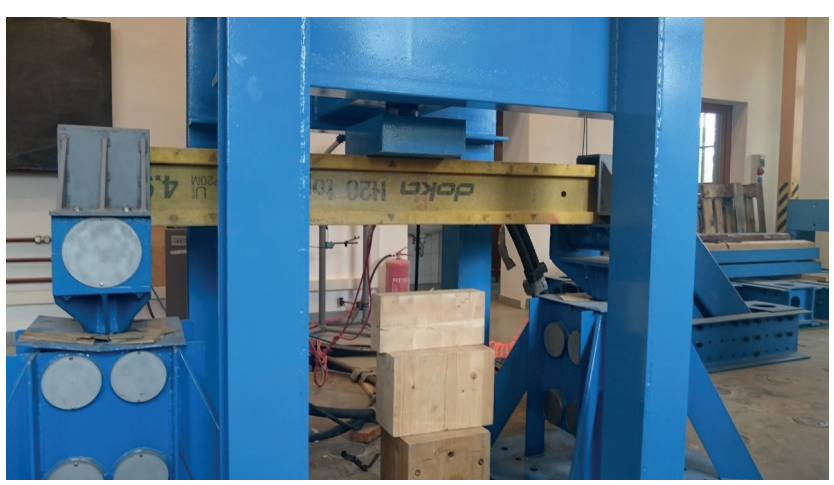

Fig. 3 MTS testing device with a specimen mounted

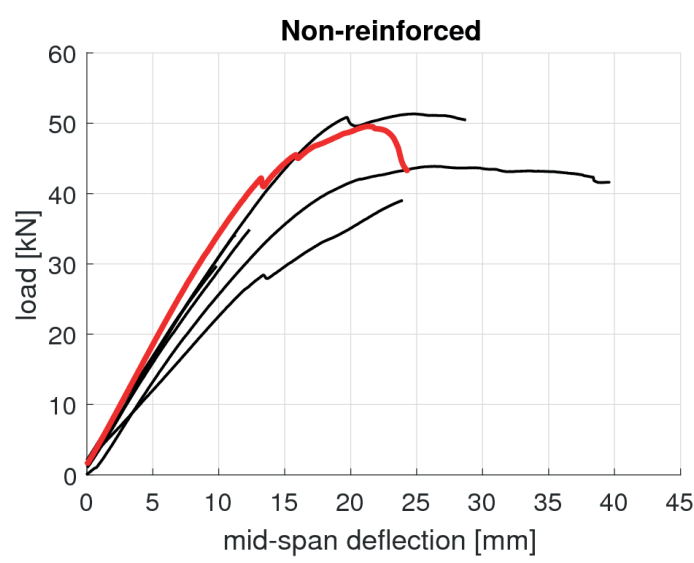

Fig. 4 Load-deflection curves of non-reinforced beams

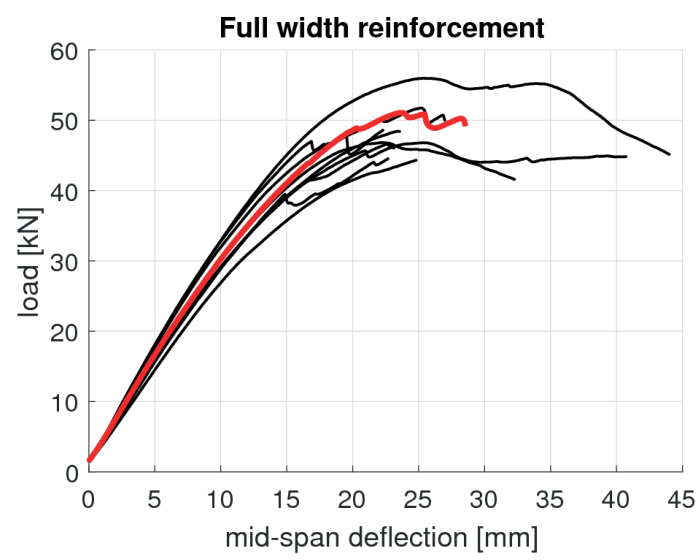

Fig. 5 Load-deflection curves beams reinforced at full width

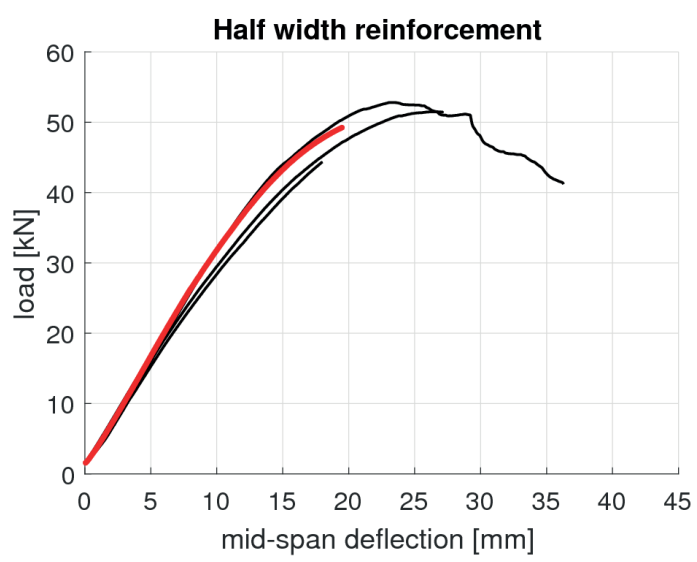

Fig. 6 Load-deflection curves beams reinforced at half width

\section{Analysis and results}

\subsection{Load-bearing capacity}

The measurements provided load-deflection data series for the test specimens. Curves for the different types of reinforcement are shown in Figures 4 to 6 with one representative curve highlighted in red in each. All curves are displayed together in Figure 7. The diagrams reveal considerable differences within the sample prompting a statistical analysis. The size of the sample is small but a normal distribution can 


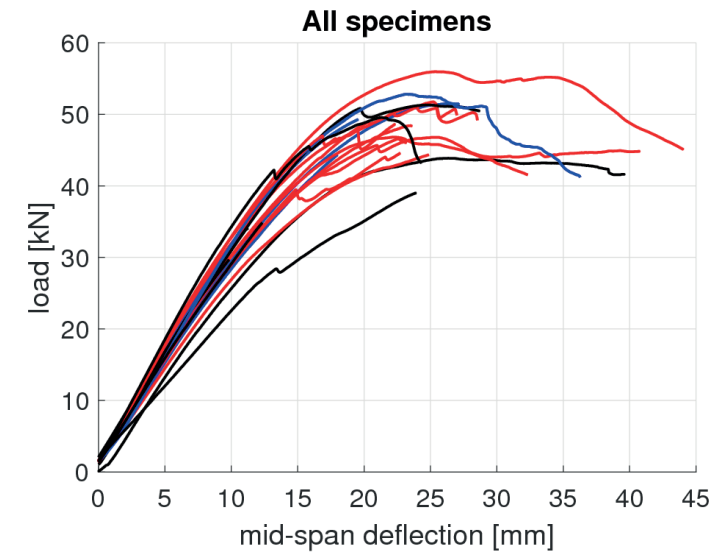

Fig. 7 Load-deflection curves of all beams; curves in Figures 4, 5, and 6 are plotted in black, red, and blue, respectively.

Table 1 Mean values, standard deviations, and relative standard deviations of ultimate loads for sample groups with no reinforcement, full width reinforcement, and half width reinforcement.

\begin{tabular}{lccc}
\hline $\begin{array}{l}\text { reinforcement } \\
\text { type }\end{array}$ & $\begin{array}{c}\text { mean value } \\
{[\mathrm{N}]}\end{array}$ & $\begin{array}{c}\text { standard } \\
\text { deviation }[\mathrm{N}]\end{array}$ & $\begin{array}{c}\text { relative standard } \\
\text { deviation [\%] }\end{array}$ \\
\hline non-reinforced & 40333 & 8192 & 20.31 \\
full width & 48487 & 3568 & 7.36 \\
half width & 47970 & 4667 & 9.73 \\
\hline
\end{tabular}

Table 2 Relative change of mean values, standard deviations, and relative standard deviations of ultimate loads for sample groups with full width reinforcement and half width reinforcement with respect to those of the sample group with no reinforcement.

\begin{tabular}{lccc}
\hline & \multicolumn{2}{c}{ change with respect to non-reinforced sample } \\
$\begin{array}{l}\text { reinforcement } \\
\text { type }\end{array}$ & mean value & $\begin{array}{c}\text { standard } \\
\text { deviation }\end{array}$ & $\begin{array}{c}\text { relative standard } \\
\text { deviation }\end{array}$ \\
\hline full width & $+20.22 \%$ & $-56.44 \%$ & $-63.76 \%$ \\
half width & $+18.93 \%$ & $-43.03 \%$ & $-52.09 \%$ \\
\hline
\end{tabular}

be assumed. In such cases the data follow t-distribution (also known as Student distribution), which is suitable to determine significant differences between data sets.

The primary aim of this research is to investigate the potential improvement of load-bearing capacity of the reinforced timber formwork beams hence the ultimate load obtained from the measurements were in focus of this analysis. The mean values, standard deviations and relative standard deviations of beams with various amount of reinforcement are shown in Table 1. Relative changes of both reinforced sample groups with respect to the non-reinforced reference groups are shown in Table 2.

The groups also show differences in terms of the minimum load-bearing capacity. The minimum values in the three groups are $29683 \mathrm{~N}, 44350 \mathrm{~N}$, and $41933 \mathrm{~N}$, respectively.
By the evaluation of the load-deflection data it can be ascertained that

- reinforcement improves load-bearing capacity by a moderate amount of $19-20 \%$,

- standard deviations and the relative standard deviation of the values decrease significantly,

- there seems to be no observable difference between the two reinforced groups with respect to average capacity as well as minimum capacities,

- the overall performance of full reinforcement is superior over non-reinforced specimens to a large degree and over partial reinforcement to a lesser degree.

It is also important to prove whether or not individual sample groups are significantly different. Since standard deviation of characteristic properties of organic materials such as timber is considerable compared to standardized factory products such as steel and the sample size is not large, a formal statistical analysis is required.

Experimental measurement data are assumed to follow normal distribution. The t-distribution (or Student distribution) is a suitable statistical test in such cases to determine whether two data sets are significantly different. This test has been applied for all three pairs of sets. The calculations have formally proven that both reinforced sample groups are different from the non-reinforced one with respect to load-bearing, whereas the two reinforced groups do not differ significantly from each other.

\subsection{Ductility and non-linearity}

A visual interpretation of the load-deflection curves indicates further differences the ultimate load values alone cannot capture. The sample group of non-reinforced beams exhibit several different failure modes within the sample. Four of the beams failed abruptly at relatively low or moderate load level without showing observable nonlinear behaviour, two specimens reached considerably higher ultimate loads with moderate ductile behaviour, and one specimen had a medium load-bearing capacity with a long plastic plateau. The respective maximum deflections of the three groups differ significantly as is apparent from Figure 4. Since extensive plastic behaviour is not a design consideration for such formwork systems, it is preferable to take into account displacements corresponding to the instant of the maximum load acting instead. The mean value of these characteristic deflections in this group is $18.62 \mathrm{~mm}$ with relative standard deviation as high as $38.75 \%$. It is clear then, that even this small sample could demonstrate the significant variations the 'pure' non-reinforced beams can show. 
Comparison with the group of beams reinforced at full width indicates that the reinforcement alters the behaviour to some degree. Now there was no premature abrupt failure. Seven specimens in the group failed at an increased ultimate load after a moderate nonlinear period near or after the limit point of the curve, while the other three specimens exhibited elongated plastic plateau without abrupt collapse. The mean value of the characteristic deflections increased to $23.81 \mathrm{~mm}$ while the relative standard deviation dropped to $5.58 \%$.

The group of beams reinforced at half width also reveals significant characteristics of the nonlinear behaviour. Three specimens showed a moderate or considerable increase of load-bearing capacity but failed abruptly with little nonlinearity before reaching a projected limit point based on the trend of the curves, that is not utilizing their full estimated potential. Two other specimens reached the limit point of their respective load-deflection curves and failed then or shortly afterwards. The mean value of the characteristic deflections also increased with respect to the non-reinforced group, to $20.43 \mathrm{~mm}$ and the relative standard deviation decreased to $23.54 \%$. The results of the groups are summarized in Table 3.

Comparison of the curves and the displacements of the two reinforced groups can reveal differences that are not apparent through the ultimate loads only. The major difference is manifested in the vanishing of abrupt collapses when the reinforcement is applied at full width instead of half width, that is a better utilization of the load-bearing potential of timber is achieved. It is a significant change of the global structural behaviour, which is also expressed in the significant reduction of standard deviation and in the increase of the mean value. It means that a sufficient amount of reinforcement renders the behaviour more predictable by eliminating premature collapses and enables more efficient utilization of the timber material.

\subsection{Stiffness}

Stiffness of the beams can be computed using the measured load-deflection curves. Elastic stiffness is defined as the slope of the curve in the linear range, where both timber and reinforcement follow linearly elastic material behaviour. The slope is produced by linear regression and given in units of $\mathrm{N} / \mathrm{mm}$. This quantity inherently involves the unknown moduli of the timber and reinforcement as well as the geometry of the loading arrangement. Values are computed for all specimens in the three groups. Table 4 shows the mean value, standard deviation and relative standard deviation for each group.
Table 3 Mean values, standard deviations, and relative standard

deviations of characteristic deflections for sample groups with no reinforcement, full width reinforcement, and half width reinforcement.

\begin{tabular}{lccc}
\hline $\begin{array}{l}\text { reinforcement } \\
\text { type }\end{array}$ & $\begin{array}{c}\text { mean value } \\
{[\mathrm{mm}]}\end{array}$ & $\begin{array}{c}\text { standard } \\
\text { deviation [mm] }\end{array}$ & $\begin{array}{c}\text { relative standard } \\
\text { deviation [\%] }\end{array}$ \\
\hline non-reinforced & 17.63 & 7.366 & 41.78 \\
full width & 23.64 & 1.382 & 5.84 \\
half width & 20.43 & 4.809 & 23.54 \\
\hline
\end{tabular}

Table 4 Mean values, standard deviations, and relative standard deviations of elastic stiffness for sample groups with no reinforcement, full width reinforcement, and half width reinforcement.

\begin{tabular}{lccc}
\hline $\begin{array}{l}\text { reinforcement } \\
\text { type }\end{array}$ & $\begin{array}{c}\text { mean value } \\
{[\mathrm{N} / \mathrm{mm}]}\end{array}$ & $\begin{array}{c}\text { standard deviation } \\
{[\mathrm{N} / \mathrm{mm}]}\end{array}$ & $\begin{array}{c}\text { relative standard } \\
\text { deviation [\%] }\end{array}$ \\
\hline non-reinforced & 2945.051 & 441.511 & 14.99 \\
full width & 3061.774 & 228.557 & 7.46 \\
half width & 3101.289 & 167.571 & 5.40 \\
\hline
\end{tabular}

The mean values in the three groups are similar with a small increase in favour of the reinforced specimens. The increment is approx. 4-5 per cent, which is expected as most researchers report insignificant increase. Moreover, some studies cite recommendations against using fibre reinforcement for enhancing stiffness [17] in light of this.

Statistical analysis on our measurement data has been carried out in a way similar to that done for load-bearing capacity. The t-test has shown that the three groups are statistically not different (i.e. all three pairs) even if higher confidence level is used than the standard. It is also observed that the standard deviation of results decreases.

\subsection{Failure}

A visual inspection of the failure modes of all the test specimens can provide further information on the behaviour in addition to those obtained from the digital data. All failures were initiated in the timber and none in the CFRP fabric or in the bond between CFRP and timber. This is in good correspondence with previous results obtained for solid spruce beams [14]. A characteristic failure mode is the rupture of the wood for tension in the bottom flange. This failure occurred in fourteen cases, more than half of the specimens. In two of these cases the failure was due to splintering tension while all the rest were initiated at weak spots of the flange, such as knots or longitudinal joints. It is well demonstrated by a non-reinforced specimen shown in Figure 8. Rupture of the flange was immediately followed by the progressive splitting of the web leading to collapse.

This failure mode is not an exclusive characteristic of pure beams. The same kind of failure of a beam reinforced at full width is shown in Figure 9. Here also the 
rupture was initiated near the middle of the span at a knot in the bottom flange. The opening of the flange again was followed by the split of the web vertically or near vertically due to tension, and finally leading to ultimate loss of load-bearing. The measured ultimate load in the case of the non-reinforced and the reinforced beam were $34867 \mathrm{~N}$ and $51733 \mathrm{~N}$, respectively.

The failure of another four specimens was due to shearing of the web. Figure 10 shows one of these cases with a diagonal crack through the entire height. Specific visible cause for the initiation of the crack is not always possible to observe. After the crack the shearing in the beam typically gave rise to the detachment of the flanges though the loading process may automatically shut at the sudden loss of load-bearing.

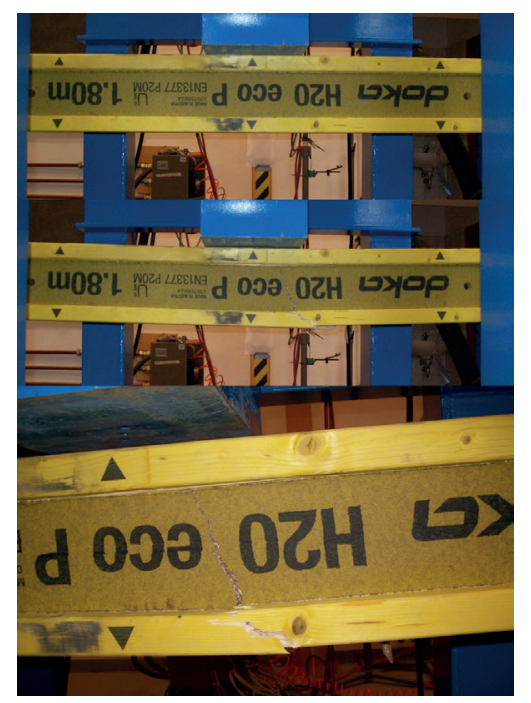

Fig. 8 Failure of a non-reinforced specimen initiated by rupture near a knot in the tension flange

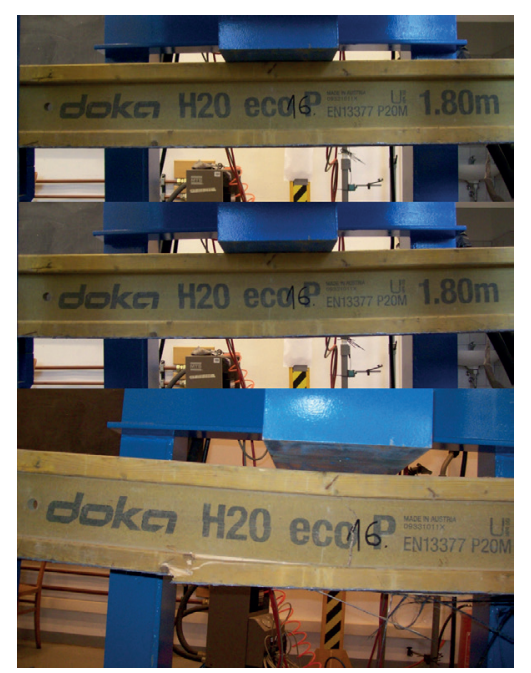

Fig. 9 Failure of a reinforced beam specimen initiated by rupture near a knot in the tension flange

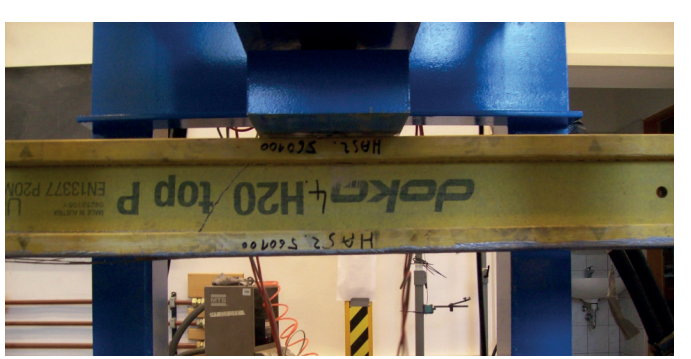

Fig. 10 Failure of a reinforced beam specimen due to shearing in the web

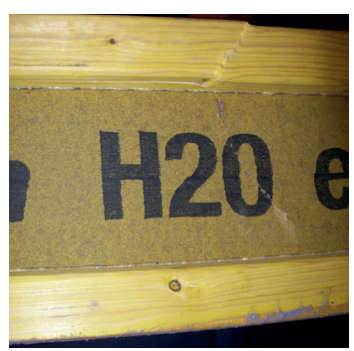

Fig. 11 Failure of a beam specimen due to compression in the top flange

The failure of the rest of the beams can be related to the top flange in various ways. In one case the joint between the flange and the web failed, in two other cases compression failure could be observed, which lead to local buckling of the fibres in the top flange, see Figure 11. In one case longitudinal split appeared in the flange under the loading instrument. In this latter case visual inspection revealed that the crack was initiated by the presence of a knot in that spot at the edge of the load area, which had a complex spatial stress state.

Relative distribution of failure modes within the groups provides us with information about the influence of reinforcement on mechanical behaviour. The predominant failure mode among the non-reinforced beams is tension of the bottom flange, either simple splintering tension or more commonly initiated at weak spots of the wood such as knots or joints. Beams reinforced at half width of the flange exhibit similar statistics, the rupture of the bottom flange at knots or joints being the most common failure mode with only one beam suffering damage in the top flange near a knot.

The behaviour of the beams reinforced at full width of the flange is mixed. Failures due to rupture of the bottom flange, compression of the top flange, defect of joint between flange and web, as well as shear splitting of the web were all observed.

Without reinforcement, vast majority of failure takes place in the bottom flange, the most intensively stressed part of the beam. A moderate amount of reinforcement increases the capacity, though failure mechanisms remain 
similar. Reinforcement on the entire surface of the bottom flange strengthen that zone to such a degree that weak spots can initiate only a part of the damage while the majority occurs at other parts previously not playing significant roles such as the web or the top flange.

\section{Conclusions}

In this research, bending testing of timber formwork beams with and without reinforcement with carbon fibre fabric on the bottom flange was carried out in order to determine potential improvement of load-bearing capacity and to analyse the structural behaviour of the complex system. Major conclusions are as follows.

- A single layer of CFRP fabric applied to the tension flange of the beam increases load-bearing capacity by approx. $20 \%$ and reduces relative standard deviation by more than half. There is no significant difference between reinforcement at full width and at half width of the flange in terms of the mean value of capacity increment. However, the case of reinforcement at full width gave better values of all statistical quantities. A significantly larger sample may highlight the differences.

- Beams without reinforcement and with two different amounts of reinforcement have significant differences in terms of displacements corresponding to maximum load. The larger the amount of reinforcement is, the higher the displacement and the smaller its standard deviation are.

- Failure of the composite beam is typically initiated in the timber and not in the reinforcement. In the sample tested in this study there was no occurrence of failure of the CFRP fabric or the bond.

- In most cases the cause of failure can be identified as weak spots or defects in the wood material, which are regarded natural features.

- CFRP reinforcement can effectively control failure of timber initiated at wood defects, such as knots. The larger the amount of reinforcement is, the smaller the probability of a sudden collapse without considerable ductility becomes. A sufficient amount of reinforcement renders the behaviour more predictable by eliminating the premature collapses and enables more efficient utilization of the timber material. Since defects produce large random scattering in data, the reinforcement also results in the significant decrease of standard deviation.
The advantages of enhancement of structural behaviour through CFRP reinforcement were proven through the testing. The moderate amount of reinforcement applied in this study could improve structural behaviour and utilize mechanical potential of timber in a considerable way. Demonstrating this improvement is useful with regard to the fact that the compound profiles studied here are composed of different shapes and materials contrary to ordinary solid sawn timber beams or even glulam beams. Also note that the complex composition gives rise to various failure modes as it was observed in the tests. Whether any particular failure mode proves predominant can be the subject of further research leading to further product development.

The application of CFRP fabric is easy, requiring no complicated technological background. Laboratory preparations were carried out effectively at low cost. Automated factory production is expected to be run cost-effectively.

The amount of reinforcement used in this study was not excessive as considerably larger amount can also be applied, even in multiple layers. The increase of the reinforcing material is expected to further improve load-bearing capacity and also stiffness to some extent. However, note that it has practical limitations since the reinforcement requires additional material, cost and work force. While a large amount of reinforcement is undoubtedly reflected in a significantly enhanced mechanical behaviour, the end product may not be necessarily competitive against other solutions. This study has shown that a small amount results in considerable improvement of capacity indicating the feasibility of this technique. An optimal amount can only be determined by a more detailed series of measurements and cost-analysis, which can be a subject of further research.

\section{Acknowledgement}

The described work was carried out as part of the 'Roadmap for Structural Changes of the University of Sopron' - nr. 32388-2/2017 INTFIN. The Ministry of Human Capacities of the Hungarian Government supported the realization of this project. The authors are grateful to Magyar Doka Zsalutechnika Kft. for providing test specimens and technical data. The authors are grateful to Sika Hungária Kft. for providing raw material for the experiments. The presented work was conducted with the financial support of the K119440 project of the Hungarian National Research, Development and Innovation Office. 


\section{References}

[1] Gentile, C., Svecova, D., Rizkalla, S. H. "Timber beams strengthened with GFRP bars: development and applications", Journal of Composites for Construction, 6(1) pp. 11-20, 2002. https://doi.org/10.1061/(ASCE)1090-0268(2002)6:1(11)

[2] Fiorelli, J., Dias, A. A. "Analysis of the strength and stiffness of timber beams reinforced with carbon fiber and glass fiber", Materials Research, 6(2) pp. 193-202, 2003. https://doi.org/10.1590/S1516-14392003000200014

[3] Li, Y.-F, Xie, Y.-M., Tsai, M.-J. "Enhancement of the flexural performance of retrofitted wood beams using CFRP composite sheets", Construction and Building Materials, 23(1) pp. 411-422, 2009. https://doi.org/10.1016/j.conbuildmat.2007.11.005

[4] Gilfillan, J. R., Gilbert, S. G., Patrick, G. R. H. "The use of FRP composites in enhancing the structural behaviour of timber beams", Journal of Reinforced Plastics and Composites, 22(15) pp. 13731388, 2003.

https://doi.org/10.1177/073168403035583

[5] Fiorelli, J., Dias, A. A. "Glulam beams reinforced with FRP externally-bonded: theoretical and experimental evaluation", Materials and Structures, 44(8), pp. 1431-1440, 2011. https://doi.org/10.1617/s11527-011-9708-y

[6] Amy, K., Svecova, D. "Strengthening of dapped timber beams using glass fibre reinforced polymer bars", Canadian Journal of Civil Engineering, 31(6), pp. 943-955, 2004. https://doi.org/10.1139/104-063

[7] Borri, A., Corradi, M., Grazini, A. "A method for flexural reinforcement of old wood beams with CFRP materials", Composites Part B: Engineering, 36(2), pp. 143-153, 2005. https://doi.org/10.1016/j.compositesb.2004.04.013

[8] Nowak, T. P., Jasienko, J., Czepizak, D. "Experimental tests and numerical analysis of historic bent timber elements reinforced with CFRP strips", Construction and Building Materials, 40, pp. 197-206, 2013. https://doi.org/10.1016/j.conbuildmat.2012.09.106
[9] Jankowski, L. J., Jasienko, J., Nowak, T. P. "Experimental assessment of CFRP reinforced wooden beams by 4-point bending tests and photoelastic coating technique", Materials and Structures, 43(12), pp. 141-150, 2010. https://doi.org/10.1617/s11527-009-9476-0

[10] Schober, K. U., Rautenstrauch, K. "Post-strengthening of timber structures with CFRP's", Materials and Structures, 40(1), pp. 27-35, 2007.

https://doi.org/10.1617/s11527-006-9128-6

[11] Triantafillou, T. C., Deskovic, N. "Prestressed FRP sheets as external reinforcement of wood members", Journal of Structural Engineering, 118(5), pp. 1270-1284, 1992. https://doi.org/10.1061/(ASCE)0733-9445(1992)118:5(1270)

[12] Buell, T. W., Saadatmanesh, H. "Strengthening timber bridge beams using carbon fiber", Journal of Structural Engineering, 131(1), pp. 173-187, 2005 https://doi.org/10.1061/(ASCE)0733-9445(2005)131:1(173)

[13] Kim, Y. J., Harries, K. A. "Modeling of timber beams strengthened with various CFRP composites", Engineering Structures, 32(10), pp. 3225-3234, 2010. https://doi.org/10.1016/j.engstruct.2010.06.011

[14] Andor, K., Lengyel, A., Polgár, R., Fodor, T., Karácsonyi, Z. "Experimental and statistical analysis of spruce timber beams reinforced with CFRP fabric", Construction and Building Materials, 99, pp. 200-207, 2015. https://doi.org/10.1016/j.conbuildmat.2015.09.026

[15] Magyar Doka Zsalutechnika Kft., Available at: www.doka.com [Accessed: 15.01.2019]

[16] Sika Csoport, Available at: hun.sika.com [Accessed: 15.01.2019]

[17] Alhayek, H., Svecova, D. "Flexural stiffness and strength of GFRPreinforced timber beams", Journal of Composites for Construction, 16(3), pp. 245-252, 2012. https://doi.org/10.1061/(ASCE)CC.1943-5614.0000261 